\title{
FEDERICO BARRETO: HACE 155 AÑOS NACIÓ EL POETA DEL CAUTIVERIO
}

\section{Carlos Alfonso Rodríguez Vilca ${ }^{1}$}

El 8 de febrero de 1862 nace en Tacna el poeta y periodista Federico Barreto, uno de los brillantes autores románticos que tiene el país. Solo tenía 17 años cuando Chile arremetió contra el Perú, por lo cual, sus cantos y poemas se insuflaron de un hondo patriotismo. Federico Barreto, fue miembro fundador del semanario El Progresista (1886) y del Círculo Vigil (1888), con su hermano José María Barreto, con quien integró el grupo denominado "La Bohemia Tacneña", en cuya revista literaria denominada Letras colaboraron: Rubén Darío, Clemente Palma, José Enrique Rodó, José Santos Chocano, entre otros autores.

Los hermanos Barreto, también dirigieron el periódico La Voz del Sur, una publicación que incomodó a los invasores chilenos porque sembró conciencia regional a través de sus escritos. Durante largos años los Barreto se mantuvieron firmes e indeclinables en la defensa de la soberanía nacional a través de las páginas de su periódico. La poesía y el periodismo fueron sus más profundas pasiones y las herramientas con las cuales defendieron sus ideas.

Federico Barreto era romántico, un eterno enamorado, pero también un rebelde contumaz, blandiendo su lira en favor de la recuperación de Tacna, tierra natal del vate, con la que tuvo un idilio apasionado, que es también otra de las emblemáticas características de los genuinos románticos, además de la melancolía, el anhelo de lo eterno, el amor profundo a la patria, la fantasía creativa y la gran musicalidad de sus cantos.

Los críticos y algunos investigadores, lo suelen proscribir de sus manuales literarios. Vaya uno a saber, ¿por qué recelos y razones? Es verdad, que en su obra hay una tangencial influencia de Gustavo Adolfo Bécquer (1836-1870), y ipor qué no habría de tenerla del más ínclito poeta romántico de habla hispana? Aquello no desmerita su obra, máxime si se puede percibir y entrever una voz propia, auténtica y original. Pues como bien dijo Víctor Mantilla, en una semblanza sobre Barreto: "Se puede y se debe imitar, pero a Byron y a Shelley. Todos los poetas escépticos y románticos del mundo caben en un poema del primero, y todos los poetas filósofos del siglo, en una solapágina del segundo".

Es probable que se le haya pretendido silenciar con disimulo, porque Federico Barreto tuvo un gran éxito con el público, como no lo ha tenido acaso ningún otro poeta peruano en vida, hasta el día de hoy. "Algo mío" (1912) la primera obra poética de Federico Barreto era esperada por un público cautivo en Arequipa, Lima, Trujillo y Tacna, sus ediciones se sucedieron hasta el día de hoy y se encuentran en la memoria de la gente y el público.

El caso de Federico Barreto solo es comparable con la del poeta colombiano Julio Flórez (1867-1923) quien logró tener un contacto emocional con el público. También los une el haber sido favorecido por la perduración de sus versos en la música popular, Julio Flórez, es autor del bello pasillo: "Mis flores negras", que entre otros, grabó Carlos Gardel. Ambos autores en su época organizaban recitales multitudinarios, era el tiempo en el que el público y la poesía se fusionaban perfectamente.

Conocí los versos de Federico Barreto, felizmente, en las calles, en las plazuelas, en los bares, en la voz de declamadores profesionales que iban y venían de pueblo en pueblo; luego en unos cuadernillos de poemas, en su propia ciudad y en las canciones. Nunca los hubiera podido encontrar en los manuales de literatura oficial, que subestiman su obra por la

\footnotetext{
Escritor y poeta peruano. Ganador de concursos literarios. Egresado de la Facultad de Comunicación, Turismo y Psicología, Universidad San Martín de Porres, Lima - Perú. Radica en Medellín-Colombia. E-mail: carlosalfonzov@hotmail.com
} 
sencillez de su literatura y la inconmensurable sabiduría de sus versos, cuando no por ignorancia.

Sin duda, Federico Barreto se encuentra entre los más grandes inauguradores de la lírica peruana del siglo XIX junto con Mariano Melgar (1790-1815), Carlos Augusto Salaverry (1830-1891), Manuel González Prada (1844 -1912) y José Santos Chocano (1875-1934). Es uno de los autores que antecedieron al gran fenómeno cultural que se produjo en el país después de la Guerra del Pacífico, en donde el imperialismo inglés influyó no solo para quedarse con territorios peruanos, islas y minas de oro.

Considero que la más importante generación de autores, pensadores, políticos, escritores y poetas peruanos nacieron o hicieron vida pública en comienzos del siglo XX: Abraham Valdelomar, Felipe Pinglo Alva, Alfonso da Silva, Antenor Orrego, Alcides Spelucín, José Carlos Mariátegui, César Falcón, Humberto del Águila, Víctor Raúl Haya de la Torre, Jorge Basadre Grohman, Luis Alberto Sánchez, Raúl Porras Barrenechea, Alberto Hidalgo, César Atahualpa Rodríguez, Gamaliel Churata, Alejandro Peralta, Arturo Jiménez Borja, Fabio Xamar y muchos otros más.

Federico Barreto, antes que Nicomedes Santa Cruzy César Vallejo, fue el más popular de los poetas peruanos; entendiendo como popular aquella expresión artística natural que es capaz de convivir, perdurar y permanecer en la memoria colectiva y en el alma nacional sin la interferencia determinante de los medios de comunicación masiva. Lugar y privilegio difícil, a los que en realidad aspiran a llegar todos los creadores; pero que es privilegio de muy pocos, como el caso excepcional de Federico Barreto.

Imagino el hermoso libro de poemas de Barreto Algo mío editado en 1912, en las manos del joven músico piurano Rafael Otero López, inspirándole la melodía del vals: "Ódiame" (Ódiame por piedad yo te lo pido/ Ódiame sin medida y sin clemencia/ Odio quiero más que indiferencia/ Porque el rencor hiere menos que el olvido...) que se escucha en todo el continente, o el poema denominado "Jaspe" que fue publicado en Revista Actualidades del 28 de febrero de 1903, y que también aparece en el libro Algo mío (1912) con el título de "Queja a Dios", libro que llegó a las manos de Carlos Gardel y José Razzano, cuando formaban el dúo Gardel-Razzano, que musicalizaron los versos de Federico Barreto, para inventar el vals "Aurora", que Gardel-Razzano grabaron en Buenos Aires, Argentina, en 1919. Sin jamás declarar la autoría de Federico Barreto.
Aurora, me has entregado, ingrata al abandono,/ y yo que tanto $y$ tanto te be querido/ni tu negra traición echo en olvido/ni disculpo tu error.. ni lo perdono./No intentes, pues, recuperar el trono/que en mi pecho tuviste y has perdido./En el fondo del alma me has berido/y en el fondo de mi alma está mi encono./Yo no podría, es cierto, aunque quisiera,/castigar como debo tu falsía;/más la mano de Dios es justiciera./Castígala, Señor, con energía:que sufra mucbo; pero que no muera.../iMira que yo la adoro todavía!

Pero si el poeta Federico Barreto es popular, no es populachero ni ramplón ni vulgar, su obra es culta, inspirada y transparente. Es un gran lector y un excelente investigador que se sumerge en lo mejor de la literatura universal para extraer la esencia, el tesoro de la palabra y convertida en joya literaria para de esta manera remitirla a sus lectores:

"Los hombres que tú miras a tu paso, son otros genios que entran a la historia:

Tú ayer sus "Noches" alumbraste al Tasso y condujiste a Dante hasta la Gloria!

Bajo tus alas de ideal pureza,

Byron impuso al Porvenir su nombre;

Esproncedalloró por su Teresa

y Víctor Hugo se hizo un Dios siendo hombre!”

Versos del poema: "A la poesía", del libro "Poesías dispersas"

"Amar, por sólo amar, es desatino, iPrefiero ser Bocaccio a ser Romeo! Mujeres, que habitáis en este mundo, Yo os amo a todas con amor profundo... ¡Venid y os brindaré mil embelesos!"

En vida Federico Barreto publicó el libro de poemas "Algo mío" (1912) y "Aromas de mujer" (1927), obras maestras de las cuales se han hecho varias reediciones porque fueron libros que tuvieron grande aceptación. Sin embargo, la obra periodística se desconoce, por lo menos para quien suscribe el presente texto que no solo quisiera leerla, sino también compartirla y divulgarla.

Federico Barreto como César Vallejo, Oquendo de Amat, Parra del Riego, Alberto Hidalgo, Alcides Spelucín y otros grandes poetas más, murió fuera de la geografía nacional, exactamente en Marsella, ciudad portuaria de 
Francia, a la que llegó en procura de salud. Se fue del mundo teniendo solo por testigo de su último respiro la mano de su amada mujer y compañera, el 30 de octubre de 1929, fecha que es considerada de luto en la ciudad de Tacna, sus restos fueron repatriados en 1968, desde Marsella e inhumados en el Cementerio General de Tacna, en donde se encuentran en la actualidad. De modo que si alguien quiere visitar la tumba del poeta enamorado debe llegar hasta Tacna.

He aquí, una brevísima pero sustantiva muestra de algunos excelsos poemas del apreciado, querido y bienamado escritor Federico Barreto, para que sus admiradores eternos disfruten sus versos, cantos y poemas. También es una buena oportunidad de relanzarlo a las nuevas generaciones para que lo compartan con otros amantes y degustadores de sensitiva poesía en el Perú, pues es uno de sus más ínclitos hijos y el más sobresaliente de sus líricos.

\section{EL BESO}

Con candoroso embeleso

Y rebosante de alegría.

Me pides morena mía,

Que te diga ¿qué es un beso?

Un beso es el eco suave

De un canto, que más que canto

Es un himno sacrosanto

Que imitar no puede el ave.

Un beso es el dulce idioma

Conque hablan dos corazones

Que mezclan sus impresiones

Como las flores el aroma.

Un beso, no seas loca,

¿Porqué me preguntas eso?

iJunta tu boca a mi boca

Ysabrás lo que es un beso!

“Algo mío”, 1912

\section{ANTES QUE TÚ}

Sonríes, al pasar, con ironía, Porque me juzgas un rival vencido... iImbécil! La mujer que has elegido, Antes que fuera tuya, ha sido mía.
En sus labios de rosa bebí un día, la esencia del licor apetecido.

¿Y tú de qué te ríes? ¿Qué has bebido?

iLas sobras de las copas de ambrosia!

Ella probó en mis brazos la ventura, para mífue la flor de su hermosura.

Yo fui -sábelo bien- isu primer hombre!

¿Hoy la posees? No me causas enojos. Cuando la besas tú, cierra los ojos y, bajando la voz, dice mi nombre...

\section{SOBERBIA}

En vano pones en no amarme empeño y te muestras conmigo huraña y fría: Yo he soñado una noche que eras mía, iY he de morir o realizar mi sueño!

En vano arrugas tu adorable ceño para probarme, ingrata, tu energía; antes de mucho, en no lejano día, Yo seré ivive Dios! iTu único dueño!

¿Te ríes? iBien!, Acepto el desafío, más debes de saber arcángel mío que si algún día me abandona el Cielo. Y otro hombre logra que tu amor irradie. Te mataré cien veces como Otelo... ¡O serás mía o no serás de nadie!

“Algo mío”, 1912.

\section{SIEMPRE MÍA}

¡Es inútil que finjas! Yo estoy cierto de que el amor que me tuviste un día entre tu pecho existe todavía, como una flor en medio del desierto.

Tu corazón reposa... No está muerto, el fuego está bajo la lava fría...

iNo lo niegues mujer! Vano sería, leo en tu faz como en un libro abierto.

Tú, como yo te mueres de tristeza y ocultas tu dolor llena de orgullo, escondiendo en tus manos la cabeza. 
Vuelve a ser buena, cede ya a mi empeño, y dime con tu voz que es un arrullo, que fui, que soy... iY que seré tu dueño!

“Algo mío”, 1912.

\section{ARRULLO}

Yo sé que en vano a ser tu dueño aspiro, yo sé que en vano ser tu esclavo espero, y, sin embargo, sólo a ti te quiero; y, sin embargo, sólo a ti te miro.

Yo sé que ni odio ni pasión te inspiro, yo sé que tienes corazón de acero, $y$, sin embargo, por tu amor me muero; y, sin embargo, por tu amor deliro.

Ignoro, niña si este amor concibes, y si al saber que sin piedad me hieres lograré, al fin, que de reír te prives.

Ignoro si aman como yo otros seres. Yo sólo sé que vivo porque vives, yo sólo sé que moriré si mueres..

“Algo mío”, 1912.

\section{FRUTA PROHIBIDA}

Cuando exhibes por la acera tu escultórica figura; el fulgor de tu hermosura ilumina la calle entera.

Ver al desnudo quisiera la línea ondulante y pura que se oprime en tu cintura y se ensancha en tu cadera...

Entonces... ¿Sabes qué haría por tu belleza excitado? ¡Pues tu carne mordería!

Y al morder cada bocado, morder me parecería un melocotón* rosado!

“Aroma de mujer”, 1927.
*El melocotón y el durazno son frutas que caracterizan la producción agrícola de Tacna.

\section{ÚLTIMO RUEGO}

Ódiame, por piedad yo te lo pido, iódiame sin medida ni clemencia! Más vale el odio que la indiferencia, el rencor hiere menos que el olvido.

Yo, quedaré si me odias, convencido de que otra vez fue mía tu existencia, del amor brota el odio en la conciencia. iNadie aborrece sin haber querido!

En pago de esta saña desmedida, te daré el alma y ésta misma vida que tu desdén a pausas me arrebata.

iTe daré todo lo que tú apetezcas! ¿Qué más quieres de mí? Ya ves, ingrata iTe ofrezco el alma para que me aborrezcas!

\section{ORGULLO}

¡Y bien! Nada me importa que la envidia me ultraje y muerda con maldad notoria. ¡Yo no conozco el miedo, y en la lidia alcanzaré el laurel de la victoria!

En vano, henchidos de un orgullo necio, quieren poner a mis ideas vallas:

iBajo el peso mortal de mi desprecio rodarán en el polvo los canallas!

¡Ah! Yo sabré reírme de las muecas de aquellos Zoilos de siniestros rostros y fabricar con sus cabezas huecas una escala que me alce hasta los astros.

Yo sabré destacarme, sin reproche, entre esa turba audaz de vilipendio, cual se destacan en la negra noche las fantásticas formas de un incendio. Mi ambición es ser grande entre los grandes, sin que nadie me humille ni me estorbe, y mirar como el cóndor de los Andes, arriba el cielo, y a mis pies el orbe. 
Yo quiero que mi orgullo, que hoy se ensancha, se traduzca en las notas de mi plectro, y que ante el sol de mi razón sin mancha, tiemblen los necios como ante un espectro.

Yo quiero avergonzar a esos estultos de críticas sin fondo y torpes mofas, apagando el rumor de sus insultos con el eco triunfal de mis estrofas.

iA combatir! No soy un ser exiguo y debo entrar en el combate rudo. Mi lema es hoy la del guerrero antiguo: "Con el escudo o bien sobre el escudo".

Henchido de una fe que no se agota, aunque me pierda lucharé sin pausa: iNo desprestigia al hombre una derrota cuando es apóstol de una buena causa!

Los críticos que darme a Dios le plugo, más que humillarme, aumentan mi decoro. "Sólo se arrojan piedras -Ha dicho Hugocontra el árbol que carga frutos de oro".
La oposición me irrita, Aquella gente caerá, al fin, bajo mi fe que abraza; cuando se pone diques al torrente, el agua lucha, se desborda y pasa.

iLucharé como un Dios! Mi frente noble nunca se humillará bajo otros brazos. Yo seré en mis batallas como el roble: iAntes que doblegado, hecho pedazos!

iAdelante! iAdelante! Mi destino destruir a mis críticos acuerda; cuando se halla una sierpe en el camino, se la debe aplastar antes que muerda.

iAdelante! No importa que la envidia me ultraje y me hiera con maldad notoria. iYo no conozco el miedo, y en la lidia alcanzaré el laurel de la victoria!

"Poesías Dispersas"

\section{MÁS ALLÁ DE LA MUERTE}

Es invierno y una noche negra, fría y tempestuosa. En la lúgubre capilla de una asilo monacal, yace el cuerpo inanimado de una joven religiosa que, agobiada por la pena, se murió como una rosa arrancada de su tallo por el fiero vendaval.

Blanco traje que realza su magnífica belleza, simboliza su inocencia, su bondad y su candor; rosas blancas en capullo le circundan la cabeza, y parece aquélla virgen que muriese de tristeza, una novia desmayada en su tálamo de amor.

El silencio que allí reina es tan sólo interrumpido por el viento que sacude las vidrieras al pasar; por el viento, y otras veces, por el tétrico graznido de los búhos que allí moran, que han formado allí su nido que atisban lo que pasa por las grietas de un altar... 
Cuatro cirios iluminan con fulgores inseguros

el cadáver de aquel ángel de belleza y de virtud, y las sombras que proyectan esos cirios en los muros, van y vienen en silencio por los ámbitos oscuros como un coro de fantasmas circundando un ataúd!

Mil rumores misteriosos, mil incógnitos sonidos, llegan vagos y confusos a la casa del Señor.. En un lúgubre concierto de sollozos y gemidos, de susurros y plegarias... de mil ecos doloridos que acongojan y estremecen, que dan pena y dan horror...

Dan las doce lentamente sobre el viejo campanario, y al vibrar en la capilla la hora tétrica y fatal, sale un monje de albo traje por la puerta del sagrario, atraviesa a pasos lentos el recinto solitario y se postra de rodillas ante el lecho funeral.

Se diría que le agobia todo un mundo de tristeza, que le mata el desconsuelo, que se muere de aflicción... ¿Por qué crispa sus dos manos? ¿Por qué inclina su cabeza? ¿Por qué tiembla? ¿Por qué gime? ¿Por qué llora? ¿Por qué reza? iHay misterios que estremecen hasta el fondo corazón!

De repente se alza el monje del helado y duro suelo, a la muerta se aproxima y la llama a media voz, y al ver que ella sigue muda, sigue fría como el hielo, la acaricia con ternura, la mirada eleva al cielo y murmura entre los dientes: "iQué injusto eres santo Dios!"

Luego clava sus pupilas en la pálida doncella, la contempla largo tiempo con recóndita piedad, y cogiendo entre sus manos una mano de las de ella, la aproxima hasta sus labios, con un ósculo la sella, y habla y gime y llora a gritos como un niño en la orfandad.

¡Dora! -Exclama- iDora mía! Te estoy viendo muda y yerta, y no creo que la muerte haya osado herirte a ti...

iMuerta tú! ¿Será posible? iNo mil veces! iNo estás muerta! Duermes... sueñas... iEstás viva! Por piedad, mi amor, iDespierta! No te mueras... no me dejes... iVive, vive para mí!

Yo era huérfano, yo estaba triste y solo en este suelo; más Dios quiso que te hallara y no tuve penas ya. ¿Lo oyes Dora? iDios lo quiso! Piedad tuvo de mi duelo y para ángel de mi guarda te envío un día desde el cielo. Tú no puedes morirte... iDios no quita lo que da!

Así, envuelta en blancos tules, coronada así de flores, te ofrecí llevar al templo y jurarte esclavitud... 
iSueño efímero! Tus padres por matar nuestros amores te encerraron en este antro de recónditos dolores, y hoy que vengo aquí a buscarte, te hallo aquí en un ataúd!

¡Pobre novia de mis sueños! iPobre tórtola sin nido! iVirgen mártir que viviste con el alma rota en dos! ¿Por qué callas si te llamo? ¿Por qué no oyes mi gemido? ¿Te cansaste de esperarme y a los cielos has partido? iVuelve, vuelve, te lo ruego... Yo te quiero más que a Dios!

Calla el monje, más de pronto, como un loco que se excita coge en los brazos a aquel ángel que en vida tanto amó, y besándole en la boca: -“iVuelve en ti, por Dios!"- le grita iToma mi alma en éste beso! iResucita! iResucita!

Toma mi alma, toda mi alma... "iVive tú, aunque muera yo!"

Un prodigio se ve entonces: Ella agita sus despojos, como herida de repente por el dardo del dolor; en sus pálidas mejillas aparecen tintes rojos; Quiere hablar, mueve los labios; ya despierta, abre los ojos... Todo alienta... iHasta la muerte! iA los besos del Amor!

Una aurora, clara y bella, a la noche ha sucedido. En el templo, que el sol baña y comienza a iluminar, yace el monje de albo traje junto al féretro tendido, y los búhos que allí moran, que han formado allí su nido, le contemplan con asombro por las grietas de un altar...

Está muerto y se diría que perdura su hondo duelo, que repite entre los dientes: "iQué injusto eres santo Dios!" Está muero. Le mataron el dolor y el desconsuelo. No halló aquí a su prometida y a buscarle se fue al cielo... iYa están juntos! iUna tumba es la tumba de los dos!

"Algo mío" 1912. 